\title{
ACTORES COLECTIVOS, ACCIONES \\ Y COMPORTAMIENTOS SOCIALES \\ EN LA LUCHA POR LA TIERRA EN EL \\ NORTE DE SINALOA, 1860-1940.
}

Pedro Cázares Aboytes

\section{Resumen}

El presente trabajo tiene como finalidad analizar las estrategias construidas por los indígenas mayos, para conservar sus tierras desde la segunda mitad del siglo XIX hasta el cardenismo. Desde la expedición de las leyes de Reforma, con la reacción de las comunidades indígenas, precedida de violencia apabullante desplegada por las élites económico-políticas de la región, así como negociaciones individuales y colectivas. La diversidad de actores sociales que fueron arribando al norte de Sinaloa, la manera en que su accionar modificó el tejido social y las pautas de vida durante los años porfiristas, serán motivo de atención. La oportunidad política que representó la revolución mexicana y

las variaciones observadas de la acción colectiva, destacan como aspectos a analizar, así como las formas de organización sindical durante los años de la posrevolución, formará parte de los tópicos a tratar.

Palabras clave: acciones colectivas, sindicatos, indígenas, cultura política rural, legislación agraria.

\section{Abstract}

This paper aims to analyze the strategies built by Mayo Indians to preserve their lands since the mid-nineteenth century to the Cardenas. Since the issue of the reform laws, with the reaction of the indigenous communities, preceded 
by overwhelming violence unleashed by economic and political elites of the region, as well as individual and collective negotiations. The diversity of social actors who were arriving in northern Sinaloa, how his actions changed the social fabric and patterns of life during the Diaz years, will be cause for attention. The political opportunity represented the Mexican Revolution and the observed variations of collective action, to highlight and analyze issues and forms of labor organization during the years of the post-revolution, will be part of the topics to be discussed.

Keywords: collective action, unions, indigenous, rural political culture, land legislation.

\section{I.- INDÍGENAS MAYOS, HACENDADOS Y AUTORIDADES:} ENTRE DENUNCIOS, DESPOJOS Y ALZAMIENTOS DURANTE EL SIGLO XIX

Hacia mediados del siglo XIX, fue aprobada por las autoridades federales la ley de desamortización de bienes eclesiásticos, la Ley Lerdo en su artículo 27, afectó a las comunidades indígenas, pues lejos de lesionar los intereses y bienes eclesiásticos finalidad formal, perturbó el ritmo de vida rural existente en este país, incluido el norte de Sinaloa, espacio geográfico que a continuación se verá. Tras varios años de aparente consenso y tolerancia a las pautas de vida de las comunidades indígenas, se rompió de manera abrupta la tranquilidad. Estas medidas no fueron del agrado de las comunidades de los indios mayos, para muestra un botón; en 1859 se rebelaron casi a la par del levantamiento de los indios yaquis del vecino estado de Sonora, lo cual obligó a emprender una campaña para batirlos, el motivo principal del levantamiento: la restitución de sus tierras, estos fueron reprimidos de manera cruenta (Cázares, 2004).

Entre 1865 y 1866 en el marco del conflicto de la intervención francesa en México, nuevamente se sublevaron los indígenas de los Distritos del Fuerte y de Sinaloa. Los líderes de los indígenas de Mochicahui fueron Juan Espinosa y Carlos Alcorcha y los líderes de los indígenas de San Miguel Zapotitlán y Camayeca, Albino Galaviz de La Bajada, quien atacó las Higueras de Zaragoza. Buscando estabilizar un poco la situación, el jefe de la Brigada de Occidente, el General Ángel Martínez decretó un indulto para los rebeldes, así como las personas y autoridades involucradas, esto encaminado a resolver los asuntos de las propiedades comunales afectadas. Ante dicho indulto, las reacciones fueron diversas, por ejemplo hubo algunos rebeldes que aceptaron indultarse, como el caso del indígena Lucas Damián del pueblo de Tehueco, distrito del Fuerte, a quien el gobierno aceptó indultar (AHGES-ICSGES, 1866: $\mathrm{s} / \mathrm{n}$ )

Desde la región serrana hasta la parte costera del distrito del Fuerte, los conflictos por la tierra involucraron toda una gama de actores, así como negociaciones entre autoridades políticas, jefes militares, hacendados y líderes indígenas. Los caminos elegidos por todos y cada uno de estos actores, fueron diversos. En el caso de las comunidades de Tehueco y Tesila, el indígena Lucas Damián el mismo que años atrás se indultó, encabezó a los quejosos de su comunidad logrando el reparto de tierra a 165 personas, destacando gran número de mujeres entre los beneficiados, además de que una parte considerable de esta comunidad eran familiares de Damián. (AMAEF, 1869: 1-18), lo cual bien podría interpretarse como una negociación el gobierno y ésta comunidad indígena. Dichas decisiones son entendibles bajo la lógica que algunos actores realizan evaluaciones acerca de las posibilidades de triunfo de movimiento disidente y otras alternativas por las que pueden decidirse (Tilly, 2000: 21-51).

Los indígenas recurrieron a mecanismos de negociación, como echar mano de representantes que lejos estuvieron de buscar el bienestar de las comunidades indígenas, sino el bienestar personal. Al no tener una personalidad jurídica que les diera voz y voto frente a las políticas liberales, al no poder expresarse libremente en estos espacios públicos, el hacendado, el letrado del pueblo y el jefe político fueron los medios por los cuales las comunidades indígenas, como actores colectivos canalizaron, ese casi inexistente espacio de expresión de su descontento.

Durante el régimen porfiriano, las compañías deslindadoras fueron las encargadas de seguir actuando sobre las propiedades indígenas, al amparo de las leyes de colonización y deslinde de terrenos las cuales abrieron más las puertas para que se cometieran un sin fin de arbitrariedades y abusos. Esta actividad descansó en gran parte en las autoridades políticas locales de los distritos, en el caso del Distrito del Fuerte, al delegársele esta responsabilidad se vieron con gran poder para decidir que tierras eran baldías o no, utilizando desde el engaño hasta la represión con fuerza, como fue el caso de Zacarías Ochoa, quien en calidad de director político de Ahome persiguió y encarceló a algunos rebeldes de la región que se resistían a los repartos de tierras baldías. (AHGES-ICSGES, 1887: 17).

Estos hombres fuertes de la región y algunos representantes políticos se 
valieron de estos cargos para amasar una gran cantidad de tierras, ya fuera para ensanchar sus propiedades, o para lucrar con ellas tanto con connacionales o extranjeros, ya sea en lo individual o representando empresas. Las reparticiones a comunidades indígenas fueron menores y en el mejor de los casos se les dieron largas. En el caso de Ahome fue el indígena Saturnino Carlón quien para sí y a nombre de otros indígenas de este poblado solicitó al Gobierno del Estado, reparto de tierras en dicho punto y de los cuales se decían poseedores.

En Charay se repitió el mismo patrón, apatía de las autoridades en atender a las comunidades indígenas, y hacer oídos sordos antes las demandas. Fue el turno de Antonio Facocame del pueblo de Charay, quien se quejó ante las autoridades estatales de que el Prefecto del Fuerte no los ponía en posesión de sus terrenos. (AHGES-ICSGES, 1888, exps. 5, 7,16: 226,229). Facocame y Carlon, optaron por tomar una ruta larga de lucha pacífica, donde las condiciones les eran totalmente adversas, pero decidieron aprovechar las redes de sociabilidad tejidas entre las comunidades años atrás cuando combatieron contra los hacendados de la región e institucionalizaron sus tácticas, en aras de llegar a poseer tierras de comunidad (Torrow, 1997).

Retomando a las compañías deslindadoras y sus acciones desplegadas en el Distrito del Fuerte hubo básicamente tres empresas de esta índole que dejaron huellas considerables en la región. Respecto a las compañías figuraron la Sinaloa Land Company', compañía deslindadora Becerra Hermanos y la compañía colonizadora y deslindadora Luis Martínez de Castro. El accionar de la SLC en las comunidades indígenas no se hizo esperar. Junto con dichas compañías, llegaron connotados hombres de negocios de otros distritos, estados, e inclusive de otros países.

Con proyectos socioeconómicos de iban desde una proyecto comunal-como fue el caso de The Credit Foncier Company²-, inversionistas extranjeros que lograron capitalizar las oportunidades que ofreció la situación que vivía, como la fractura entre los hacendados de la región, llegando en algunos casos hasta el homicidio, por la competencia de tierras cercanas los puntos de irrigación.

La mayor parte de estas disputas no pueden comprenderse considerando solo las facetas funcionales u organizativas. Tras ellas se dibuja un trasfondo más denso y complejo. Las pujas que por muy diversos motivos se entablaban entre las redes sociales que configuraban las facciones influyentes en cada distrito, división político-administrativa de Sinaloa. El resultado de esa compleja trama de relaciones que articulaban vínculos antiguos y novedosos fue una fuerte inestabilidad de las autoridades locales en la zona, una dimensión más opaca pero no menos decisiva de las disputas políticas de la época que todavía no ha sido estudiada con demasía.

Esa situación permitió que Johnston aprovechara para acumular grandes extensiones de tierra, cuya finalidad era incorporarla a la empresa agroindustrial que junto con Zacarías Ochoa, el cuál coadyuvó el despojo de una importante obra irrigación de aquellos años, como era el canal de Tastes, obra que con muchos sacrificios, inversión y envuelta en una fuerte polémica, fue realizada por los colonos de CFCO. A pesar del empeño de los colonos, no todos eran aptos para el duro y desgastante trabajo de desmonte, destroncamiento, excavación y acarreo de la tierra suelta.

Contrario a los principios de la colonia, se emplearon un cierto número de indígenas mayos, a los cuales se les asignó un salario de 50 centavos por jornada de ocho horas de trabajo, más una ración de maíz y fríjol (Ortega, 1978: 143). Johnston concretó acuerdos para apoderarse de manera ventajosa tanto de la tierra -predio Los Mochis- como el agua -canal de Tastes-. Johnston obtuvo una concesión para tomar el agua del río Fuerte y construir el canal de Los Mochis, el cual "extrañamente coincidía con el trazo de el canal de Tastes". Al mismo tiempo se dedicó a comprar el script circulante emitido por al Kansas City Invesment Company al menos del $10 \%$ de su valor. Ese papel podía hacerse valido ya sea en dinero o con derechos sobre el agua del canal, y cuando Johnston tuvo el control de la mayor parte del script exigió la entrega del canal (Gill, 1983:64).

Las iniciativas para modificar la propiedad de la tierra tuvieron resultados gratificantes para los hombres de poder, así como para los inversionistas extranjeros. La situación prevaleciente en el primer lustro del siglo XX, fue la siguiente: el total de tierras empleadas en diversas actividades productivas oscilaba alrededor de 98,150 hectáreas. De ese número de tierra 16,565 eran terrenos de temporal, 8,275 eran tierras irrigadas. Por esos años la superficie total del Distrito del Fuerte se encontraba clasificada de la forma siguiente: 345,382 eran tierras sin cultivar, de las cuales 205,000 hectáreas eran de pastizales y 135,000 eran de bosques. (AMAEF, 1905, $\mathrm{f} s / \mathrm{n}$ ). Un panorama más claro de los resultados que había tenido los conflictos por la tierra en el norte de Sinaloa, sus nuevos propietarios y la manera que se utilizaba la tierra, lo brinda el cuadro siguiente: 


\begin{tabular}{|l|l|l|l|l|}
\hline \multicolumn{1}{|c|}{ Propietario } & \multicolumn{1}{|c|}{ Ubicación } & Extensión & \multicolumn{1}{c|}{$\begin{array}{c}\text { Actividad } \\
\text { Productiva }\end{array}$} & Valor Fiscal \\
\hline $\begin{array}{l}\text { Francisco } \\
\text { Orrantia }\end{array}$ & La Constancia & 5000 hectáreas & Azúcar & 112390 pesos \\
\hline $\begin{array}{l}\text { Zakany } \\
\text { Sucesores }\end{array}$ & La Florida & 1500 hectáreas & “uuuu & 22721 pesos \\
\hline $\begin{array}{l}\text { Sinaloa } \\
\text { Sugar Co. }\end{array}$ & Los Mochis & 1400 hectáreas & uuuuu & 33850 pesos \\
\hline $\begin{array}{l}\text { Sinaloa } \\
\text { Sugar Co. }\end{array}$ & El Águila & 3800 hectáreas & «uuuu & 144740 pesos \\
\hline
\end{tabular}

Fuente: Archivo Municipal Ayuntamiento El Fuerte

Como puede observarse, las agroindustrias azucareras estaban concentrando tierra en cantidades considerables, tierras trabajadas por hombres que alguna vez fueron propietarios de dichos terrenos.

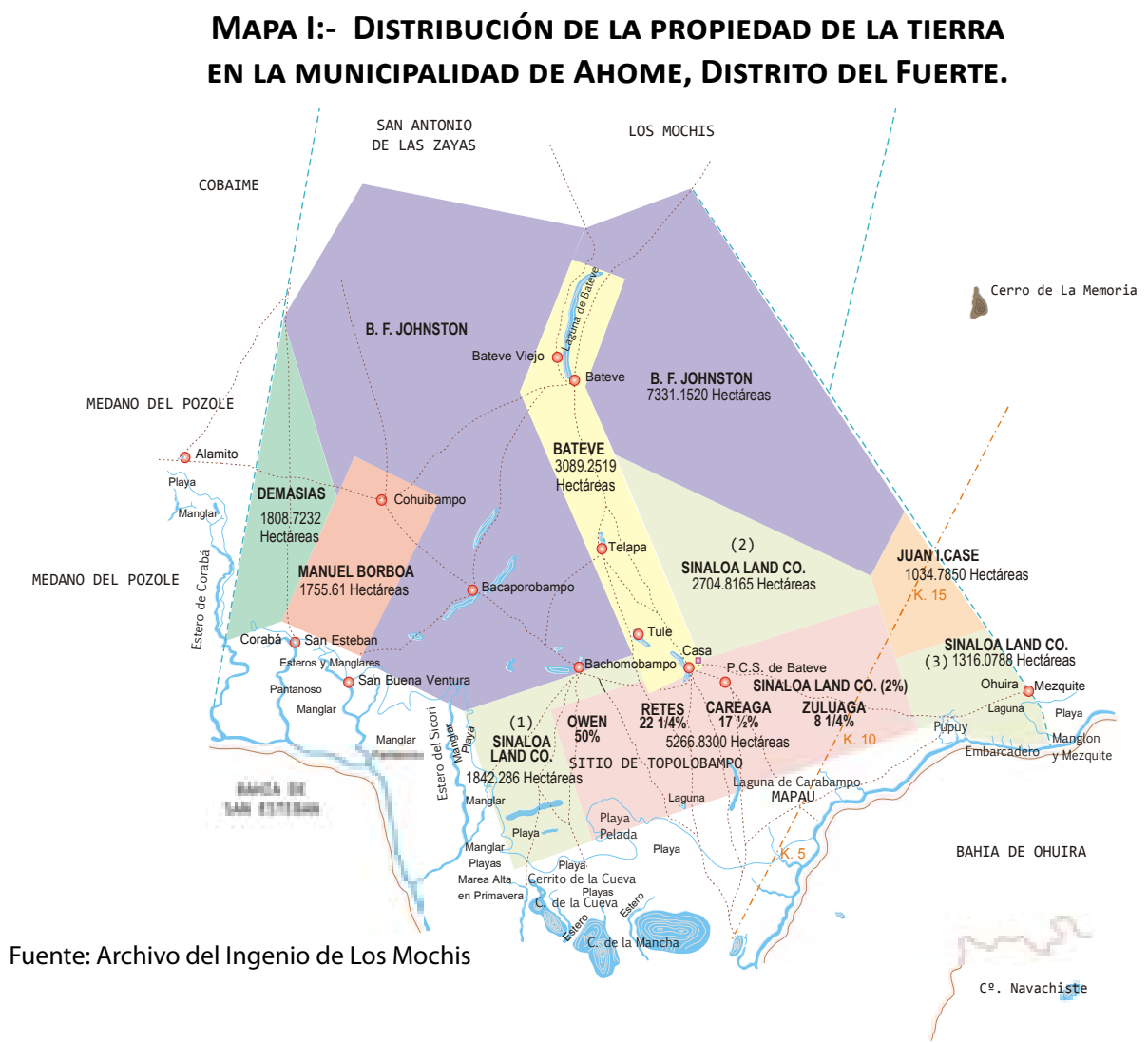

\section{II.- EMPRESA, TRABAJADORES Y LUCHA REVOLUCIONARIA}

as agroindustrias azucareras eran los núcleos donde la tierra se estaba concentrando en cantidades considerables, pues los ingenios azucareros necesitaban grandes cantidades de tierras sembradas de caña de azúcar, tierras que eran trabajadas por hombres que algunas veces fueron propietarios de dichas tierras. La empresa que por esos años empezaba a marcar distancia respecto sus vecinos, era la Sinaloa Sugar Companies, que después se convertiría en la United Sugar Companies.

\section{IMAGEN I.- EL INGENIO AZUCARERO DE LOS MOCHIS} DE LA UNITED SUGAR COMPANIES

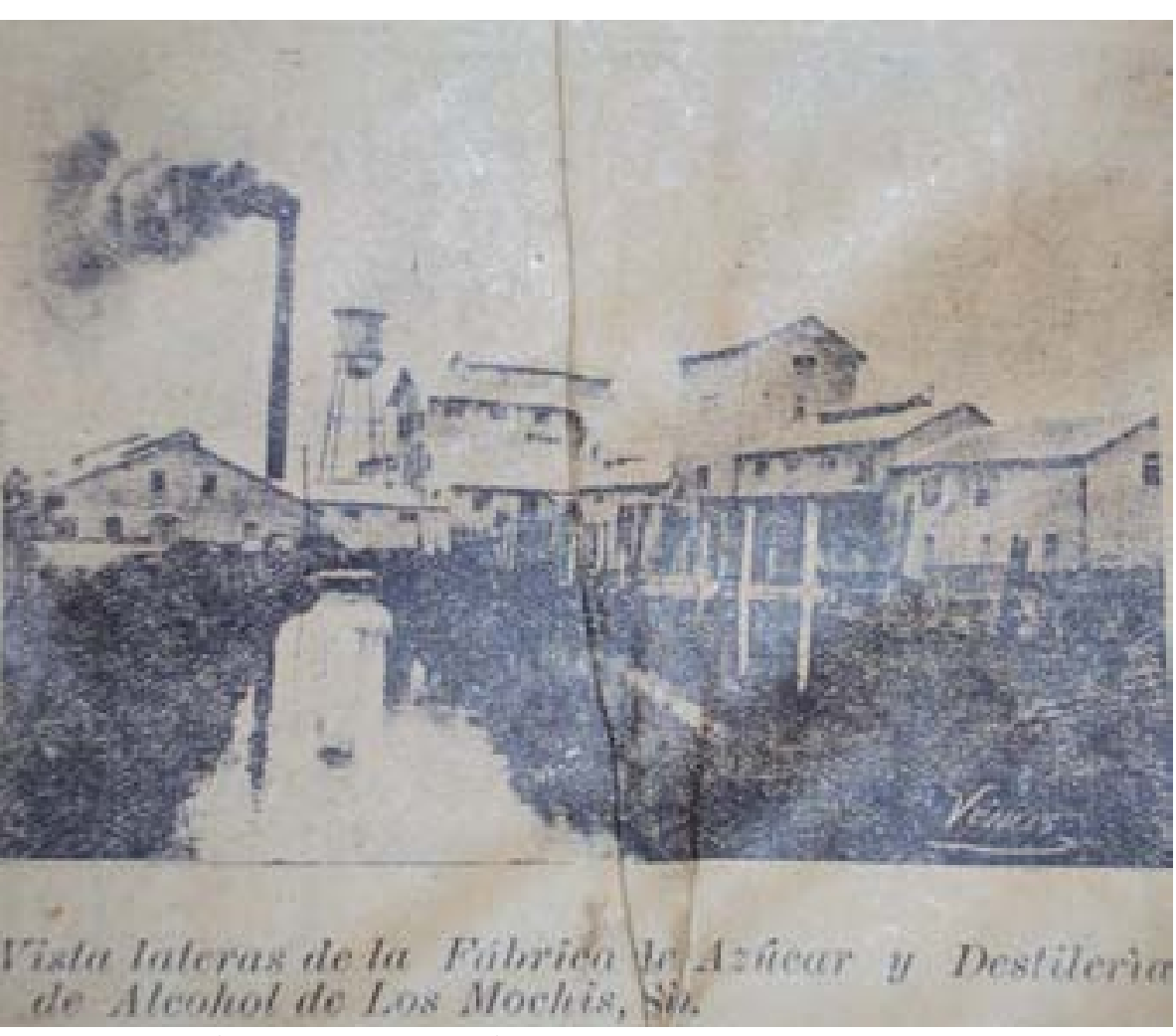

Fuente: El Demócrata Sinaloense, Mazatĺn, 1 de enero de 1926. 
Resulta conveniente antes de hablar de los obreros y campesinos, com entar acerca de la parte patronal, la empresa. En este caso, al hablar de la United Sugar Companies ${ }^{3}$, es adentrarse en algo más que una empresa, fue un espacio donde se fueron tejiendo relaciones que hicieron posible la constitución de este gran emporio agroindustrial, cuyo creador y cerebro de esta compañía fue el estadounidense Benjamín Francis Johnston.

Johnston anunció que iba a pagar 75 centavos diarios y en efectivo, lo cual motivó que gran parte de los trabajadores de la región se fueran a trabajar a esta factoría ante la oferta del norteamericano comparada con los 2 pesos al mes y la fanega de maíz devengada en calidad de sueldo. Esta última cuestión de sumar aparte del sueldo en efectivo un pago especie - una fanega de maíz en este caso - pudiera indicar una mejora en el nivel de vida, pero por lo general fue un medio a lo largo del tiempo para mantener bajos los salarios y en casos extremos prescindir completamente de los salarios en dinero.

Pronto el ingenio Los Mochis tuvo bajo su nómina alrededor de 500 trabajadores. (Gill, 1983:68). Desde la fundación del ingenio Los Mochis se formaron divisiones en el área cañera, designándoseles como campos: 1, 2 así sucesivamente hasta llegar al número 14, además de sietes campos más denominados según su lugar de localización. En cada uno había comisarios eran quienes controlaban las tiendas de raya - así como los aperos de labranza, arados, palas, machetes, etc, donde diariamente se abastecía a la gente que laboraba a cargo de los mayordomos (Schobert, 1998: 107).

Simultáneamente, los extranjeros seguían apropiándose de las tierras de los indígenas como había sucedido a lo largo del porfiriato, además de gozar de reconsideraciones de pagos de derechos de propiedad rústica, como fue el caso de A. F Krohn quien solicitó se le redujera el avaluó de la propiedad conocida con el nombre de sierra de Navachiste. Quejas de índole laboral se empezaron a manifestar en lugares tan apartados del Distrito del Fuerte como la población de Choix donde Ramón Islas y Alejo Ceceña representando a los trabajadores de los comerciantes de este lugar solicitaron ante el Gobierno del estado que interpusiera su influencia a fin de que se les concediera el descanso dominical. (AHGES-ICSGES, 1910-1911: $\mathrm{f} \mathrm{s} / \mathrm{n}$ ).

Mientras el grueso de la gente se encontraba en sus actividades cotidianas, en la cabecera del distrito del Fuerte las primeras oleadas de la revolución mexicana se empezaron a sentir con el pronunciamiento de

${ }^{3}$ En adelante USCO. actores muy diversos, en este caso José María Ochoa (AHGES-ICSGES, 1910: $f \mathrm{~s} / \mathrm{n}$ ). Un hacendado porfiriano que por esos años mostraba claras señales de decaimiento económico y político, se lanzaba a esta lucha armada. Pero todavía con capacidad económica y liderazgo para movilizar contingentes de hombres armados considerables. Dicha situación, no es casual, pues los que ya tenían experiencia de mando en la vida civil tendían a ser los que comandaban también en tiempos de guerra (Fraser, 2003: 15). El reclutamiento combinaba la apelación de lazos personales entre las estrategias desplegadas para lograr ganar adeptos. Rodolfo Ibarra fue comisionado para que incrementara las filas rebeldes a través de la invitación a los indígenas mayos del Distrito del Fuerte, a quienes les ofrecieron que en caso que triunfara la causa revolucionaria se les serían restituidas sus tierras.

Los indios mayos empezaron a participar en esta lucha. Muchos de ellos se desempeñaban como trabajadores del ingenio El Águila, ingenio Los Mochis o empleados con los antiguos colonos que ahora surtían de materia prima a ambas factorías. Concretado el triunfo de la revolución maderista, se invitó a los soldados a volver a sus casas, a seguir trabajando pacíficamente sus tierras. Los mayos no tenían tierras, ni podían volver a las haciendas donde los hacendados seguían con un poder no quebrantado y peor aún tomarían represalias sin duda contra los que participaron en el movimiento armado.

Una paz muy efímera, pues al poco tiempo los efectos del derrocamiento de Madero por parte de Victoriano Huerta. En ese orden de cosas, los mayos fueron conminados por José María Robles, cuestión que recibió buena acogida dentro de los indígenas de San Miguel Zapotitlán secundándolos los gobernadores indígenas de Mochicahui, Charay, Ahome, Sivirijoa y Tehueco (Quintero, 1978: 684). En el caso de Robles, se ve a un hombre mestizo casado con una mujer indígena, recibido y aceptado de tiempo atrás que se había ganado la confianza y el afecto entre la comunidad, guarda mucha similitud con la idea de un el líder en ciertos movimientos sociales debe en cierto sentido ser miembro del mismo grupo y tener suficientes rasgos culturales en común para poder identificarse con ellos (Moore, 1996: 33).

Los indígenas mayos se fueron concentrando en Mochicahui y San Miguel, cuyo cuartel central estaba en Jaguara y su líder fue Felipe Bachomo. Para mediados de 1913, entraron en acción y cayeron de sorpresa sobre el pueblo de Mochicahui y atacaron las haciendas de José María Cázarez, Rosario Valdez, Emigdio Rojo, Ramón Hernández, entre otros. Intentando pacificar la situación las autoridades estatales emitieron un indulto para los sublevados del norte de 
Sinaloa, el cual no fue aceptado (Ramírez, 1998: 77). Lejos de aceptar el dicho ofrecimiento, su respuesta fue un rotundo no, además que diversificaron sus formas de descontento para con el gobierno en turno, se sentían defraudados, que no les habían cumplido la promesa de regresarles sus tierras.

Una forma de atacar las propiedades de los hacendados de San Miguel Zapotitlán, donde no pocos de los alzados habían trabajado anteriormente, consistió en enterrar un canal que irrigaba las tierras de los hacendados, de ésta forma arruinaron los terrenos sembrados al no tener el agua necesaria (AHGESICSGES, 1913: $\mathrm{f} s / \mathrm{n}$ ). En el marco de este tipo de estos conflictos políticos, este tipo de acciones se vuelven algo recurrente, la búsqueda de blancos muy concretos, no al azar, ya sea contra ciertos individuos que detenten el poder, o como en este caso, contra la infraestructura física del gobierno (Ortiz, 1996: 69)

Pero no todos los indígenas se rebelaron en contra del gobierno. Hubo algunos que desde el inicio de la revolución, huyeron hacia el monte, o bien, se refugiaron en el vecino estado de Sonora, esperando que aminorara la violencia para retornar a tierras sinaloenses Por otra parte, está el caso del norteamericano Frederick Drewien, que participó al lado de indios mayos en la toma de Navojoa, le trajo dificultades a su padre Win Drewien quien fue llamado a rendir cuentas al respecto, e inclusive fue encarcelado por el síndico de Los Mochis. ¿Cómo explicarse estas actitudes tan inusuales por parte de la población, tanto de indígenas mayos, norteamericanos u otros? este tipo de fenómenos no sólo son actuados, sino también son vividos, causando no pocas veces, cambios abruptos en el comportamiento (Vovelle, 2000: 192)

Por esos mismos días, los indígenas del pueblo de San Miguel Zapotitlán protestaron enérgicamente contra la testamentaría de Teodoro $\mathrm{M}$. Valenzuela porque pisoteaba las propiedades de los indígenas al emprender obras de irrigación invadiendo las propiedades de los mayos, todo ello en perjuicio de sus tierras cultivadas. Los pobladores de dicho gasentamiento nuevamente apostaron a radicalizar sus acciones y echaron mano de la táctica de enterrar el canal que la testamentaria de Teodoro Valenzuela había venido construyendo, con los mismos resultados. Al parecer, la revolución mexicana se convirtió en una oportunidad política para que los trabajadores del norte de Sinaloa manifestaran su descontento, particularmente los trabajadores de la USCO.

Cabe recordar que muchos de ellos formaron parte de las filas revolucionarias, de hecho algunos seguían todavía en pie de guerra al mando de Felipe Bachomo. Simultáneamente a los hechos de armas en la región, otros actores decidieron actuar por vías más apegadas a la legalidad. La primera huelga por parte de los obreros contra la USCO fue el año de 1914. No había entonces organización sindical, su única demanda: reducción de la jornada de trabajo a ocho horas, los encargados de hacer llegar esta demanda fueron Daniel Ascencio, Ramón Castro y los hermanos Telésforo y Juan Armenta. Los obreros desorganizados no supieron usar la única arma en sus manos, la huelga, entonces la empresa se impuso (Gill, 1983: 136).

Si bien no hubo otras huelgas o movilizaciones de obreros de cierta importancia, esto no quiere decir que hubo una paz absoluta. Aparte ya no era solo un ingenio era dos ingenios: El Águila y Los Mochis. Por otro lado, los otros ingenios - La Florida de la familia Zakany, así como el ingenio La Constancia de Francisco Orrantia y Sarmiento-, ya no estaban funcionando como ingenio azucarero solo se dedicaba a otras actividades agrícolas. Estas dos factorías venían funcionando años atrás que El Águila y el ingenio Los Mochis. Para esos años, la USCO ya era la propietaria del ingenio La Florida, organismo que absorbió su infraestructura, sus tierras, trabajadores y con ellos iba interiorizada también su experiencia laboral previa. Retomando a Thompson todos estos trabajadores de los ingenios La Florida, La Constancia, El Águila y Los Mochis cabe mencionar que la mayor parte sintieron la crucial experiencia en términos de cambio en la naturaleza y la intensidad de la explotación laboral. (Thompson, 1989: 208).

Aunque los obreros presentaron una sola demanda, la reducción de la jornada de trabajo a ocho horas solamente, esto nos revela una cuestión esencial: la importancia del tiempo, habían aprendido de que el tiempo es oro. Si bien la empresa reprimió severamente cualquier inconformidad en su interior, muchos de sus trabajadores ya eran parte de la rebelión de los indios mayos liderados por Felipe Bachomo, quien fue uno de los tantos e ignorados miembros del tercer Batallón sumados a este movimiento a los cuales se les prometió tierras, defeccionaron en masa en San Blas el 22 de octubre de 1914 (Quintero, 1978: 723)

En sus primeas incursiones respetaron las propiedades de la USCO, y se enfocaron -como ya se mencionó-, a castigar a los hacendados y saquear sus comercios. Hay mucha especulación al respecto, que si existieron o no tratos secretos entre Johnston y Bachomo. Las de Bachomo se unieron a los villistas, comandadas por Orestes Pereyra y Juan M. Banderas y a partir de ese momento ni las propiedades de la USCO estuvieron a salvo, lo anterior quedó evidenciado en el ataque a Los Mochis del 16 al 19 de noviembre de 1915. Posteriormente vino el declive de la rebelión indígena, ahora sumada al bando villista, pues se 
les propinaron sendas derrotas obligándolos a replegarse al Estado de Sonora, donde finalmente el 5 de diciembre de 1915 en Movas, Distrito de Alamos, Sonora, los generales Juan M. Banderas, Fructuoso Méndez, Francisco Urbalejo, Jesús Trujillo y Felipe Bachomo aceptaron un ofrecimiento de amnistía (Olea, 1993: 154, Fuentes, 2005: 123, Alarcón, 2006, 235).

Bachomo, decidió disolver sus núcleos y le pidió a su gente regresaran a las márgenes del Río Fuerte a seguir luchando por sus tierras siguieron la recomendación de Bachomo, un mes después de la ejecución de Bachomo, indígenas de Mochicahui se presentaron ante el presidente municipal del Fuerte solicitando se les regresaran las tierras que anteriormente eran de su propiedad, sin éxito alguno. A nivel estatal y federal, tanto Ángel Flores en tierras sinaloenses, como Venustiano Carranza, mantuvieron una postura de represión frente a obreros y campesinos, no desentonando con los intereses de los aminorados grupos porfirianos sinaloenses, irónico tomando en cuenta que eran gobernantes surgidos de la gesta revolucionaria (AHGES-ICSGES, 1916: 548, Vidales, 2002).

En lo que materia laboral se refiere, el grueso de los trabajadores tenían menos posibilidades que sus demandas tuvieron resonancia en la junta central de conciliación y arbitraje, pues acababa de ser nombrado encargado de dicha junta el licenciado Celso Gaxiola Andrade, persona ampliamente identificada con los intereses de la parte patronal. Aparte de soportar largas jornadas laborales, bajos salarios y la constante vigilancia de la guardia blanca de la USCO, los trabajadores tuvieron también que preocuparse por los reclutamientos arbitrarios y forzosos efectuados por enganchadores militares provenientes del estado de Sonora, sin que hubiera autoridad o particular que intercediera por ellos (AHGES-ICSGES,1918: 86,89, ES, 1919: 4-5)

a leva era una acción conjunta de autoridades militares, policiales, judiciales y vecinos connotados de la región, era un instrumento de coerción (Fradkin, 2006: 130). En ese marco de empoderamiento, la USCO no indemnizaba a los trabajadores o familiares de éstos, quienes laborando en sus diversas labores tanto de fábrica como de campo hombres, mujeres y niños, en ocasiones perdieron hasta la vida, logrando evadir las responsabilidades por las cuales eran requeridos como patrones, aún cuando la constitución de 1917, claramente protegía a obreros y campesinos, dando muestra que las autoridades municipales, estatales y junta de conciliación y arbitraje.

\section{III.- ORGANIZACIONES OBRERAS EN EL NORTE DE SINALOA Y SUS AVATARES}

La política laboral y agraria hasta la mitad de los años veintes había sido favorable al sector empresarial. El gobierno estableció un reglamento que exentaba del reparto agrario a las propiedades dedicadas al cultivo y procesamiento de la caña de azúcar. Para 1924, la USCO seguía violando flagrantemente la carta magna emanada de la Revolución Mexicana y robando a sus trabajadores cuatro o más horas diarias de su trabajo. Esta cuestión no era únicamente a nivel regional o estatal, si no a nivel nacional en muchas de las zonas cañeras se levantaron a luchar por sus derechos, esto de dificultaba por los conflictos entre las organizaciones nacionales tanto obreras como campesinas, se disputaban el control de los trabajadores.

No conforme con eso, la empresa decidió suprimir la gratificación anual que erogaba por sus cuatro mil trabajadores (Morett y Pare, s/f: 163). El descontento estalló pero, aprovechando la experiencia anterior, antes de iniciar el movimiento se constituyó el 3 de Abril de 1924 el sindicato de trabajadores de oficios varios con cincuenta y dos trabajadores de la USCO, el cual por razones obvias, no obtuvo el registro en las dependencias oficiales. Un día después fundaron el sindicato de obreros y campesinos del Ingenio de San Lorenzo, dicho ingenio estaba ubicado en Higueras de Zaragoza, propiedad de los alemanes Casa Melchers, comerciantes y prestamistas asentados en Mazatlán.

Los dirigentes de este movimiento Martiniano Quintanilla, José Caravantes, Juan Díaz, Jesús Esparragoza, Carlos Yepes, Agustín Ruiz, José Elguezabal y otros trabajadores todos ellos del radio de la fábrica, presentaron sus peticiones: Jornada de 8 horas, aumento de salarios y reconocimiento sindical. Ambas organizaciones emplazaron a huelga a sus respectivos patrones, quienes rechazaron las peticiones e inician en complicidad con el presidente municipal Camilo J. Carlón, una feroz persecución de Martiniano Quintanilla y José Fregoso a quienes se les encarceló bajo la acusación de ser bolcheviques.

Ante esto, el 17 de abril de 1924 los demás líderes realizaron un acto político al que asistieron un numeroso grupo de trabajadores (Ramírez, 1987: 42, Morett y Pare, s/f: 161, Gill, 1983: 136). El estallido de la huelga programada para el 14 de Mayo se aplazó, entonces el Comité Nacional de la CROM envió a un representante, Mario Martínez con la misión de persuadir a los trabajadores inconformes para que desistan de la huelga. 
Sin embargo, los ánimos estaban encendidos, eso ya no se podía detener y Mario Martínez, y la CROM no les quedó más remedio que encabezar dicho movimiento, el cual estalló de manera simultánea tanto en el ingenio Mochis como en San Lorenzo. A pesar de su falta de experiencia, los huelguistas lograron paralizar las labores del ingenio San Lorenzo y una gran parte de la USCO. Los empresarios, autoridades municipales y estatales iniciaron la ofensiva amedrentando a los grupos de trabajadores para que regresaran a sus labores. En San Lorenzo, 50 personas aproximadamente y en la USCO más de un centenar, aceptaron convertirse en esquiroles. En el caso de la USCO donde había tomado más fuerza este movimiento, los esquiroles laboraron en calidad de cautivos, detrás de las cercas de la empresa y custodiados por las guardias blancas del ingenio y la policía municipal, para que no fueran a ser linchados.

El sindicalismo obrero campesino se enraizó después de esta segunda huelga, así lo manifiesta el hecho que en un lapso de 3 años, se formaron 11 sindicatos en la parte norte de Sinaloa en sus ya tres municipios Ahome, El Fuerte y Choix. Los sindicatos conformados fueron los siguientes. Estos sindicatos estaban incorporados a la Federación de Sindicatos del Estado de Sinaloa y a su vez a una central nacional que era la confederación regional obrera mexicana, cabe destacar que ninguno de estos sindicatos obtuvo su registro ante la Junta Central de Conciliación y Arbitraje. Sin embargo, cabe mencionar que no todos los trabajadores escogieron la organización sindical.

IMAGEN II: CASAS DE LOS TRABAJADORES DE LA UNITED SUGAR COMPANIES

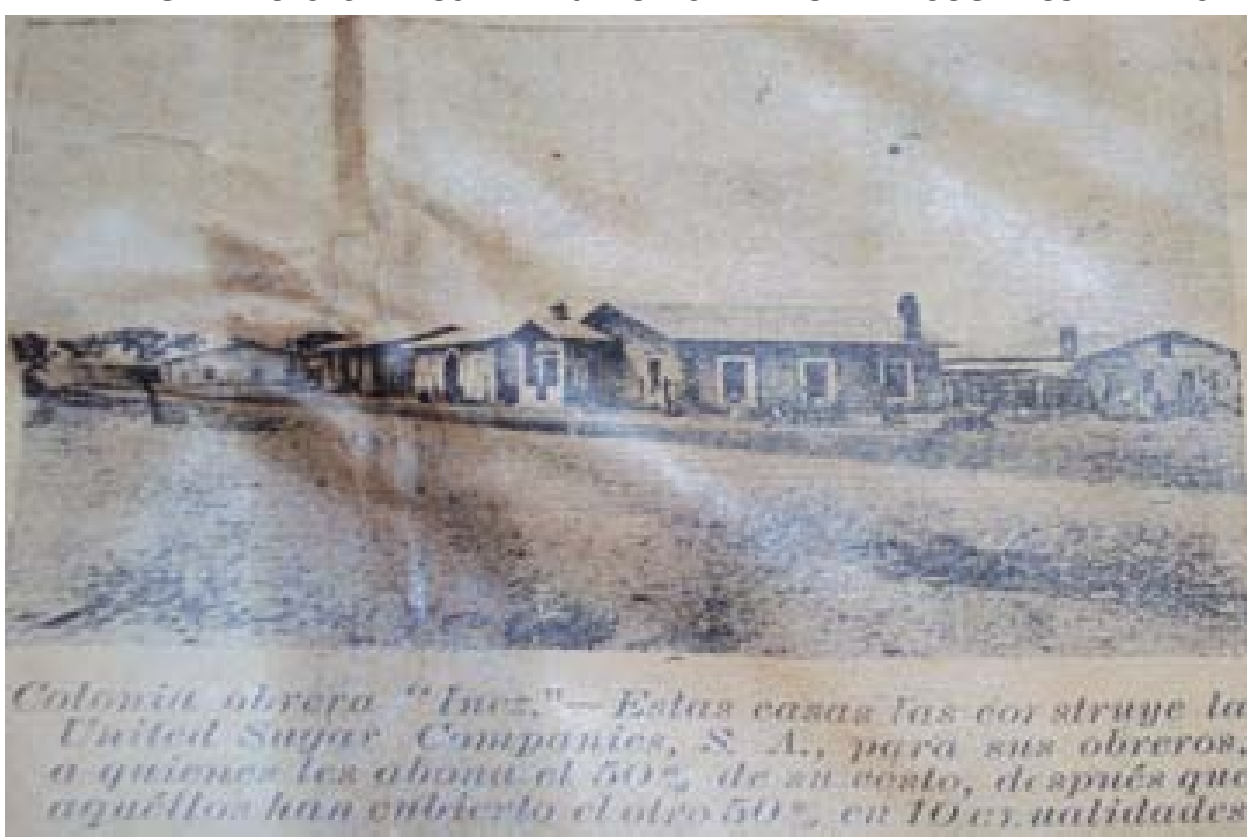

\section{IV.- LOS DISCURSOS DE LOS SECTORES SUBALTERNOS}

Por otra parte, la movilización sindical no fue la única estrategia de acción colectiva por parte de obreros y campesinos en el norte de Sinaloa. Con la promulgación de la constitución de 1917, con el antecedente de la ley del 6 de enero de 1915, se convirtió en una grieta por donde los actores sociales buscarían encauzar sus demandas dentro del marco legal para obtener una parcela. Aquí en este punto, es importante preguntarse: ¿quiénes realizaron las peticiones de tierras o de reconocimiento de derechos?, ¿fueron individuales o colectivas?, ¿a qué instancia fueron dirigidos los oficios?, ¿los litigios fueron únicamente contra hacendados?, ¿cuáles eran los argumentos que utilizaron para defenderse?, ¿lograron negociar siempre a su favor? ¿Sus discursos fueron pacíficos o altamente incendiarios?

Por ejemplo, los vecinos de la congregación de San José del municipio de Ahome, Sinaloa se dirigieron al Gobernador del Estado, "solicitando dotación de ejidos con fundamento en el artículo 3o de la ley de 6 de Enero de 1915." (ES, 1917: 3). Los solicitantes eran 90 jefes de familia, de los cuales 39 ya eran poseedores de pequeñas y medianas parcelas, mientras que el resto eran jornaleros quienes eran empleados en los ingenios azucareros de la región. En este caso la respuesta fue positiva para los solicitantes, pero no para toda la colectividad, esto entre otras cosas porque los terrenos solicitados no eran propiedad de ningún hacendado - los propietarios eran Félix Buelna y Eduardo López, sin embargo no todos fueron agraciados con una parcela.

Lo anterior nos habla que estos actores sociales no se remitieron a una sola posibilidad - la lucha sindical-, sino que sabían irse adaptando a las circunstancias y echar mano de todas las opciones de acción colectiva. Pero fue hasta una década después cuando la vía legal empezó a ser utilizado con mayor frecuencia por los sectores subalternos. Probablemente esto se debió a que anteriormente la lucha se estaba realizando únicamente desde la organización sindical.

n lo que se refiere a la reactivación de este espacio de expresión política, destaca el caso de la comisaría de Las Chumas, jurisdicción de San Blas, municipalidad del Fuerte, quienes plantearon su solicitud de dotación de la forma siguiente: "ante usted con el debido respeto exponemos: el artículo 3o de la Ley de 6 de enero de 1915 elevada al carácter de la Constitución da derecho a los pueblos para ser dotados de ejidos que necesitan.- los habitantes de este lugar están en apremiante necesidad de tierras ejidales por carecer completamente de ellas y ser netamente agricultor.- [...] a usted C. Gobernador en nuestro derecho pedimos.- 1‥ Que nos tenga por presentado solicitando 
para la Comisaría de "Las Chumas" la dotación de tierras ejidales.-2o. Que se sirva usted certificar al pie de la presente solicitud a la categoría política de nuestra Comisaría.- 3o. Que sirva usted a remitir la presente solicitud a la Comisión Local Agraria.- 40. Que sirva usted recordar a la Comisión Local Agraria al remitirlos estos documentos el plazo de cuatro meses que le fija el artículo 30 del decreto de 17 de abril de 1923.- 50. Que se nos acuse recibo de la presente solicitud a este propio lugar al domicilio del C. Ramón V. Acosta a quien design (ES, 1927: 20).

No pocas cosas se pueden comentar respecto a este documento. Primero, no se mostraron desafiantes ante las autoridades, ellos informaban, buscaban mostrar cierto disimulo, no una organización previa y trabajada de esta estrategia política, aunque el espacio para formular estas peticiones colectivas eran las asambleas colectivas; sin embargo, buscaban presentarse como si su petición hubiera sido espontánea, carente de malicia. Los pueblos y sus apoderados legales utilizaron la retórica oficial, para apoyar sus peticiones y conseguir lo poco que fueran a ceder las élites dominantes.

Otro ejemplo que permite ver algunas de las estrategias discursivas de estos actores, fue el caso de la petición de los habitantes de Toro, Choix, que a continuación se inserta íntegramente:

"Los que suscribimos [...] con el debido respeto exponemos [...] desde hace tiempo inmemorial existe el pueblo de nuestra vecindad, compuesto ahora aproximadamente de trescientos cincuenta habitantes. - En la actualidad carecemos de los elementos más [sic] indispensables para nuestra existencia y desarrollo, pues estamos reducidos a la mas [sic] completa miseria debido a que algunos individuos validos del apoyo que siempre disfrutaron de parte de las autoridades del lugar, despojaron a este pueblo de los terrenos con que una superficie de más [sic] de dos sitios de ganado mayor" (ES,1927:12)

En este caso, los habitantes del poblado el Toro, demostraron conocer la jerarquía de las instancias políticas y judiciales ante quienes apelar, cuando decidieron hacerlo, así como la necesaria intermediación de un personaje letrado. Por otro lado, están apelando a instrumentos jurídicos coloniales -mercedes, reales cédulas, recopilación de Indias-, porque todo indica un conocimiento de la legislación promulgada por los gobiernos emanados de la revolución mexicana, tanto en favor como en contra de las comunidades.

Por otra parte, sabían que exhibir su pobreza, su ignorancia, su debilidad frente a la codicia de los hacendados y la corrupción de las autoridades, implorar por el porvenir de nuestros hijos y por la subsistencia y bienestar de las nuevas generaciones, para cubrir nuestras más apremiantes necesidades, para la manutención de nuestras familias (ES, 1927: 12, ES, 1931: 3, ES, 1932: 1-7), no eran argumentos que los mostraran débiles frente a las instancias a que se dirigieron; para nada, sino que buscaban aprovechar al máximo el discurso oficial, reinterpretándolo para sus intereses.

Aquí nuevamente vale la pena echar un vistazo a cuantas manifestaciones colectivas por la tierra se realizaron. Entre 1925 y 1937, se publicaron en el periódico oficial como parte de los trámites obligados; 34 publicaciones, de ese total 18 de los trámites realizados fueron hechas por comunidades del municipio de El Fuerte, 8 fueron efectuados por poblados del municipio de Ahome y el resto por 8 puntos poblacionales del municipio de Choix. A continuación se muestra un cuadro con las solicitudes de tierras planteadas por los trabajadores:

\section{CUADRO II: ACCIONES LEGALES REALIZADAS POR LOS TRABAJADORES} SOLICITANDO TIERRA

\begin{tabular}{|l|l|c|}
\hline \multicolumn{1}{|c|}{ POBLACIÓN } & \multicolumn{1}{|c|}{\begin{tabular}{c}
\multicolumn{1}{c|}{ INTENCIÓN DEL } \\
ESCRITO
\end{tabular}} & AÑO \\
\hline $\begin{array}{l}\text { Comisaría del Rincón, } \\
\text { El Fuerte }\end{array}$ & $\begin{array}{l}\text { Solicitud de dotación de } \\
\text { tierras }\end{array}$ & 1925 \\
\hline $\begin{array}{l}\text { Comisaría Las Chumas, } \\
\text { El Fuerte }\end{array}$ & $\begin{array}{l}\text { Solicitud de dotación de } \\
\text { tierras }\end{array}$ & 1925 \\
\hline $\begin{array}{l}\text { Comisaría de Aliso, } \\
\text { El Fuerte }\end{array}$ & $\begin{array}{l}\text { Solicitud de dotación de } \\
\text { tierras }\end{array}$ & 1925 \\
\hline Toro, Choix & Restitución de tierras & 1927 \\
\hline Las Grullas, Ahome & $\begin{array}{l}\text { Solicitud de dotación de } \\
\text { tierras }\end{array}$ & 1931 \\
\hline Batequis, Choix & $\begin{array}{l}\text { Solicitud de dotación de } \\
\text { tierras }\end{array}$ & 1931 \\
\hline Yecorato, El Fuerte & $\begin{array}{l}\text { Solicitud de dotación de } \\
\text { tierras }\end{array}$ & 1932 \\
\hline Bajada del Monte, El Fuerte & Restitución de tierras & \\
\hline Tepehuaje, El Fuerte & $\begin{array}{l}\text { Solicitud de dotación de } \\
\text { tierras }\end{array}$ & \\
\hline
\end{tabular}




\begin{tabular}{|l|l|c|}
\hline \multicolumn{1}{|c|}{ POBLACIÓN } & \multicolumn{1}{|c|}{$\begin{array}{c}\text { INTENCIÓN DEL } \\
\text { ESCRITO }\end{array}$} & AÑO \\
\hline La Florida, Ahome & $\begin{array}{l}\text { Solicitud de dotación de } \\
\text { tierras }\end{array}$ & 1932 \\
\hline Los Tastes, El Fuerte & $\begin{array}{l}\text { Solicitud de dotación de } \\
\text { tierras }\end{array}$ & 1932 \\
\hline Baroten, El Fuerte & $\begin{array}{l}\text { Solicitud de dotación de } \\
\text { tierras }\end{array}$ & 1932 \\
\hline Ohuira, Ahome & $\begin{array}{l}\text { Solicitud de dotación de } \\
\text { tierras }\end{array}$ & 1932 \\
\hline Ocolome, El Fuerte & $\begin{array}{l}\text { Solicitud de dotación de } \\
\text { tierras }\end{array}$ & 1932 \\
\hline Chinobampo, El Fuerte & $\begin{array}{l}\text { Solicitud de dotación de } \\
\text { tierras }\end{array}$ & 1932 \\
\hline Zapote, El Fuerte & $\begin{array}{l}\text { Solicitud de dotación de } \\
\text { tierras }\end{array}$ & 1932 \\
\hline Mahone, El Fuerte & $\begin{array}{l}\text { Solicitud de dotación de } \\
\text { tierras }\end{array}$ & 1932 \\
\hline Tasajera, Choix & $\begin{array}{l}\text { Solicitud de dotación de } \\
\text { tierras }\end{array}$ \\
\hline El Guayabo, Ahome & $\begin{array}{l}\text { Solicitud de dotación de } \\
\text { tierras }\end{array}$ & 1932 \\
\hline Torres, El Fuerte & $\begin{array}{l}\text { Solicitud de dotación de } \\
\text { tierras }\end{array}$ \\
\hline Carricitos, El Fuerte & $\begin{array}{l}\text { Solicitud de dotación de } \\
\text { tierras }\end{array}$ & $\begin{array}{l}1932 \\
\text { dotación de tierras }\end{array}$ \\
\hline La Capilla, El Fuerte & $\begin{array}{l}\text { Solicitud de dotación de } \\
\text { tierras }\end{array}$ & $\begin{array}{l}1932 \\
\text { tierras }\end{array}$ \\
\hline Huepaco, El Fuerte & $\begin{array}{l}\text { Solicitud de dotación de } \\
\text { tierras }\end{array}$ & \\
\hline Guadalupe, Choix & & \\
\hline
\end{tabular}

\begin{tabular}{|l|l|c|}
\hline \multicolumn{1}{|c|}{ POBLACIÓN } & \multicolumn{1}{|c|}{$\begin{array}{c}\text { INTENCIÓN DEL } \\
\text { ESCRITO }\end{array}$} & AÑO \\
\hline El Rincón, El Fuerte & $\begin{array}{l}\text { Solicitud de dotación de } \\
\text { tierras }\end{array}$ & 1935 \\
\hline Las Compuertas, Ahome & $\begin{array}{l}\text { Solicitud de dotación de } \\
\text { tierras }\end{array}$ & 1935 \\
\hline Loretillo, Choix & $\begin{array}{l}\text { Solicitud de dotación de } \\
\text { tierras }\end{array}$ & 1935 \\
\hline El Colexio, Choix & $\begin{array}{l}\text { Solicitud de dotación de } \\
\text { tierras }\end{array}$ & 1935 \\
\hline El Nacimiento, Choix & $\begin{array}{l}\text { Solicitud de dotación de } \\
\text { tierras }\end{array}$ & 1937 \\
\hline Tabelojeca, Ahome & $\begin{array}{l}\text { Solicitud de dotación de } \\
\text { tierras }\end{array}$ & 1937 \\
\hline El Reparo, Choix & $\begin{array}{l}\text { Solicitud de dotación de } \\
\text { tierras }\end{array}$ \\
\hline Rancho de Islas, Choix & $\begin{array}{l}\text { Solicitud de dotación de } \\
\text { tierras }\end{array}$ & 1937 \\
\hline Aguajito, Ahome & $\begin{array}{l}\text { Solicitud de ampliación de } \\
\text { tierras }\end{array}$ \\
\hline
\end{tabular}

FUENTE: PERIÓDICO OFICIAL DEL ESTADO DE SINALOA, AÑOS CONSULTADOS 1925-1937

De esos 34 trámites, 32 fueron solicitudes de tierras, 2 restituciones de tierras y una ampliación de tierras de ejido. Resultan particularmente interesantes las dos restituciones de tierras y la solicitud de ampliación, en términos de revisar los argumentos empleados ante las instancias gubernamentales. Los casos de las poblaciones que solicitaron restitución; son Toro, Choix - ya revisado - y los vecinos de Bajada del Monte, El Fuerte. El escrito de la petición de restitución de tierras es el siguiente: [...] ante usted exponemos: que el artículo 27 de la Constitución, el articulo 3으, de la Ley de 6 de enero de 1915 elevada al carácter de Constitucional y de la Ley de Dotación y Restituciones, de 21 de marzo de 1929, dan derecho a los pueblos para que sean dotados de los ejidos que necesiten [...] el pueblo que representamos, está en apremiante necesidad de tierras ejidales, por carecer completamente de ellas y de ser un pueblo netamente agricultor. (ES, 1932: 2-3.)

En esta petición pasado, presente y futuro se entrecruzaban; por un lado, 
los pobladores de la Bajada del Monte, - muy similar a los habitantes de Toromostraban estar al tanto de las disposiciones legales. La ley les abrió una posibilidad para buscar hacer valer su personalidad jurídica que les diera voz y voto frente a las políticas gubernamentales. En ese momento pudieron recurrir a una serie de mecanismos de negociación, los actores colectivos canalizaron ese casi inexistente espacio de expresión para encauzar su descontento, dichos actores estaban percibiendo las transformaciones generadas en el ámbito político. Entre los discursos construidos de manera colectiva, se encuentra una lectura común del pasado producto de experiencias compartidas y formativas lo cual se puede encontrar en una organización de un proyecto de vida, en base del espacio de experiencia y proyectando un horizonte de expectativa.

En este punto, Serge Bernstein (1998: 392-398) aporta elementos para analizar la situación cuando nos comenta que "la cultura política supone a la vez una lectura común del pasado y una proyección hacia el futuro vivida en grupo [...] la cultura política como la cultura misma se inscribe en el marco de las normas y de los valores que determinan la representación que una sociedad se hace de ella misma, de su pasado, de su futuro". De manera colectiva, los pueblos encontraron las vías para seguir presentándose en la arena legal usando la palabra escrita, se escribía y se leía colectivamente en las comunidades. Diferentes estrategias eran utilizadas por los mismos sujetos, dependiendo de la queja, del objeto y del receptor de la demanda. Las peticiones colectivas son una manifestación de opinión; que es finalmente una opinión política.

\section{V.- LA ORGANIZACIÓN SINDICAL Y SUS ACCIONES}

Durante la segunda mitad de los años veinte, los gobernadores Manuel Paez y Macario Gaxiola, continuaron solapando las acciones antisindicales y agraristas en tierras sinaloenses. Durante el gobierno de Manuel Páez, varias indicaciones se habían realizado desde la ciudad de México al ejecutivo estatal, para que lo socializara entre los patrones, para que hicieran efectiva dicha demanda, haciendo caso omiso a ello (Cázares, 2002). Por su parte el general Gaxiola no hizo nada por un grupo de obreros que fueron despedidos injustamente. Esto mismos obreros se presentaron personalmente ante el aludido general angosturense, y no lograron una solución satisfactoria (AILM, 1928: 2-8).

En el municipio de Ahome con 30,394 habitantes y una población económicamente activa de 10500 habitantes en 1930, los dos ingenios que cerraban durante periodos de tres meses al año, ocupaban el $75 \%$ del total de la fuerza de trabajo de todo el municipio - un total de 8,300 personas United Sugar Companies de Los Mochis, con 5,295 trabajadores y San Lorenzo de Higueras de Zaragoza con 930. A partir de los meses de febrero y marzo de 1929 estas dos factorías así como compañías empacadoras de tomate y otras legumbres empezaron a despedir en masa a sus trabajadores.

Los trabajadores de ambos ingenios se empezaron a organizar y surgió el sindicato de obreros, campesinos y agraristas de San Miguel, fundado el 8 de septiembre de 1929, con 170 miembros, la unión de empaques y campos tomateros de Los Mochis, fundado el 8 de marzo de 1930, con 132 miembros y la unión feminista de obreras y empleadas del ramo tomatero y similares, fundado el 9 de marzo de 1930, 161 miembros.

En el municipio del Fuerte se fundó el sindicato de obreros, campesinos y agraristas de Mochicahui, el 1 de Septiembre, con 320 miembros, el sindicato de campesinos "Fuerza y Acción" de la hacienda de Sufragio, fundado el 14 de abril de 1930, con 208 miembros (Ramírez, 1987: 59-64). Ya no solo eran sindicatos pertenecientes a la industria azucarera los que se estaban organizando, si no que se estaba conformado un frente común de trabajadores de otras actividades agroindustriales, quienes también optaron por la vía sindical.

Entre los líderes, destaca Carlos Ramón García Ceceña, quién jugaría un papel importante, entre otras cosas por haber impulsado la organización de una convención obrero campesina de la zona norte del estado de Sinaloa en la ciudad de Los Mochis del 16 al 20 de marzo de 1929, con la asistencia de cinco organizaciones aparte del Sindicato Industrial de Oficios Varios de Los Mochis que fueron: sindicato de obreros y campesinos del ingenio San Lorenzo, unión de estibadores y jornaleros, sucursal 1, Topolobampo, unión de trabajadores marítimos y terrestres de Topolobampo, sindicato de pescadores de Topolobampo y sindicato agrario de campesinos de la desembocadura del río Fuerte "Guadalupe Rangel" (Ramírez, 1987: 95-97). La respuesta de la USCO fue cruda: despidos masivos, desalojos de las viviendas de los trabajadores, amenazas y homicidios.

La intransigencia de la USCO y la visible complicidad del gobierno en todos sus niveles convenció a los trabajadores que para enfrentar a la empresa y al gobierno, era necesario una organización de mayor envergadura. Por eso, tras el despido de sus dirigentes, estos se dedicaron de lleno a la organización de los trabajadores ya no solo de la zona del ingenio o del norte de la entidad, si no a 
extender sus lazos con los obreros de los otros ingenios del centro del estado de Sinaloa. Los líderes trabajaron en los municipios del Ahome, El Fuerte, Choix, Guasave, Culiacán y Mazatlán, involucrando no solo trabajadores de la industria azucarera.

La idea de los sindicatos generales de agrupar multitudes varios gremios y oficios, no era únicamente no era únicamente con la idea de crear una organización fuerte o lograr un nivel de solidaridad y fraternidad, si no también evitar que los no sindicalizados se convirtieran en esquiroles de estos y aparte un mayor respaldo de recursos de cualquier tipo, ya sea económico o en especie (Hobsbawm, 1979: 188).

El movimiento contra la USCO recibió apoyo en colectas de víveres y dinero realizadas por la clase trabajadora tanto en el mismo municipio de Ahome como en el municipio de El Fuerte y Guasave, para el sostenimiento de la huelga, por ejemplo el sindicato de pescadores de Topolobampo destinó el $50 \%$ de su pesca diaria. Sus acciones no carecieron de racionalidad, pues cabe mencionar que los dominados se rebelan abiertamente impulsados por cálculos económicos, vínculos y responsabilidades (Joseph, 2002).

La magnitud del conflicto estaba adquiriendo proporciones insospechadas y para esos días ya había trascendido la fronteras de la entidad, y en la ciudad de México se convocó a una reunión donde trabajadores de la industria azucarera a nivel nacional decidieron realizar un paro de media hora en todos los ingenios del país en solidaridad con los obreros y campesinos del ingenio Los Mochis.

De tal forma, USCO de manera conjunta con representantes de empresarios del centro y del sur de Sinaloa desplegó labores de propaganda y recolección de firmas, con el fin de evitar se introdujeran ciertos elementos nocivos en el proceso selección de representantes ante la Junta Central de Conciliación y Arbitraje del Estado de Sinaloa, en la convención del día primero de diciembre de 1934 para elegir a dichos representantes para el periodo 1935- 1936 (AILM, 1934, 4-12).

En 1937 fue un acontecer de paros laborales, con la finalidad de disminuir la molienda de la caña lo mayor posible, esto motivo que la USCO se quejara ante las instancias federales. Ceceña promovió el acuerdo de que debían de ese momento en adelante parar todas las unidades laborales pertenecientes a la empresa, incluidos campos, fábrica y hasta la planta eléctrica que proporcionaba servicio de energía eléctrica, agua, servicio de teléfonos y una planta de hielo, pues él se desempeñaba como operador en esas instalaciones. Sacaba el switch de las líneas de alta tensión y cortaba el suministro de toda la población y además que se paralizaba todo el sistema de bombeo.

Adoptaron esa táctica cada vez que la empresa no quería recibir a los representantes del sindicato, los cuales notificaban a García Ceceña lo acontecido, quien inmediatamente procedía a realizar dicha maniobra, cuestión ante la cual la USCO cedía momentáneamente. Este tipo de actos evasivos, morosos o de insubordinación son una forma de resistencia no abierta frente a quienes detentan el poder (Scott, 2000: 22).

El 12 de junio de 1937 la unión de obreros y campesinos del norte de Sinaloa decidió promover un paro total, y lo novedoso en este planteamiento de sus demandas es que por primera ocasión figuró la petición de dotación de tierras, cuestión en la cual al parecer no estaban de acuerdo todos los obreros pues el código agrario de esos años dejaba fuera de la posible dotación a los obreros. Como muestra de apoyo, los trabajadores de la empacadora de conservas Los Mochis S.A, decidieron implementar las mismas medidas para que fueran echados los trabajadores contratados para boicotear las actividades de proselitismo de los trabajadores azucareros y legumbreros ( $L N, 1938: 2$ ).

EI 9 de diciembre de 1938 se entregaron 39 posesiones que amparaban igual número de ejidos y beneficiando a un número 4663 trabajadores con un total 83,870 hectáreas. Los accionistas norteamericanos de la USCO no aceptaron la expropiación agraria, y prueba de ello fue que en 1939 organizaron un expediente llamado "Exhibit 8-X ", que constaba de mapas, planos y fotografías.

En la reclamación presentada ante la Comisión de reclamaciones agrarias de Estados Unidos de América y del gobierno mexicano (Rivera, 2001: 102). Varios norteamericanos en lo individual se defendieron ante la afectación y por la vía legal estuvieron gestionando el regreso de sus propiedades con argumentos de diversa índole. Por ejemplo Enrique Korfhage y George Drake, ambos empleados de la USCO, tenían arrendado y con promesa de venta un predio de 35 hectáreas propiedad de la Compañía Agrícola de Los Mochis, subsidiaria de la USCO, desde el 16 de mayo de 1925, ubicado en el punto denominado "Las Compuertas", que a raíz de la solicitud de expropiación de las propiedades de la USCO, comprendida su subsidiaria ya aludida, este predio fue señalado como afectable, esto motivo que ambas personas, Drake y Korphage se dirigieran el de abril de 1937, al jefe del departamento agrario de la capital de México, para que ese predio no fuera afectado (ARAN, 1938: 1-36).

En la mismo situación se encontraba el norteamericano Hubert Mulkey, quien en nombre de la sociedad Hubert Mulkey y Compañía tenia arrendado y con promesa de venta, un predio de 29 hectáreas propiedad de la compañía 
explotadora de las aguas del río Fuerte, S.A, y al igual que el caso anterior dicho predio fue señalado como explotable y formaría parte del Ejido Las Compuertas, Mulkey con el fin de impedir esa acción se dirigió el día 5 de junio de 1937, al gobierno federal. En ambos casos agregaban que no procedía la afectación por ser pequeñas propiedades, más no presentaron títulos de propiedad solo de promesa de venta y finalmente la afectación se llevó a cabo la expropiación de 2,502 hectáreas de riego y monte bajo para dotar a 396 personas, que constituyeron el ejido Compuertas (ARAN, 1938: 48-78).

Estos y otros ejidos dieron vida a la Sociedad de Interés y Crédito Agrícola y Emancipación, Con el nacimiento de esta sociedad se cierra una etapa y comienza otra etapa, la cual merece el concurso de otro trabajo de investigación minucioso pues rebasa el espacio temporal fijado al comienzo de este trabajo.

\section{MAPA II.- PROPIedAdes de LA USCO CERCA Del INGeNIO LoS MOCHIS}

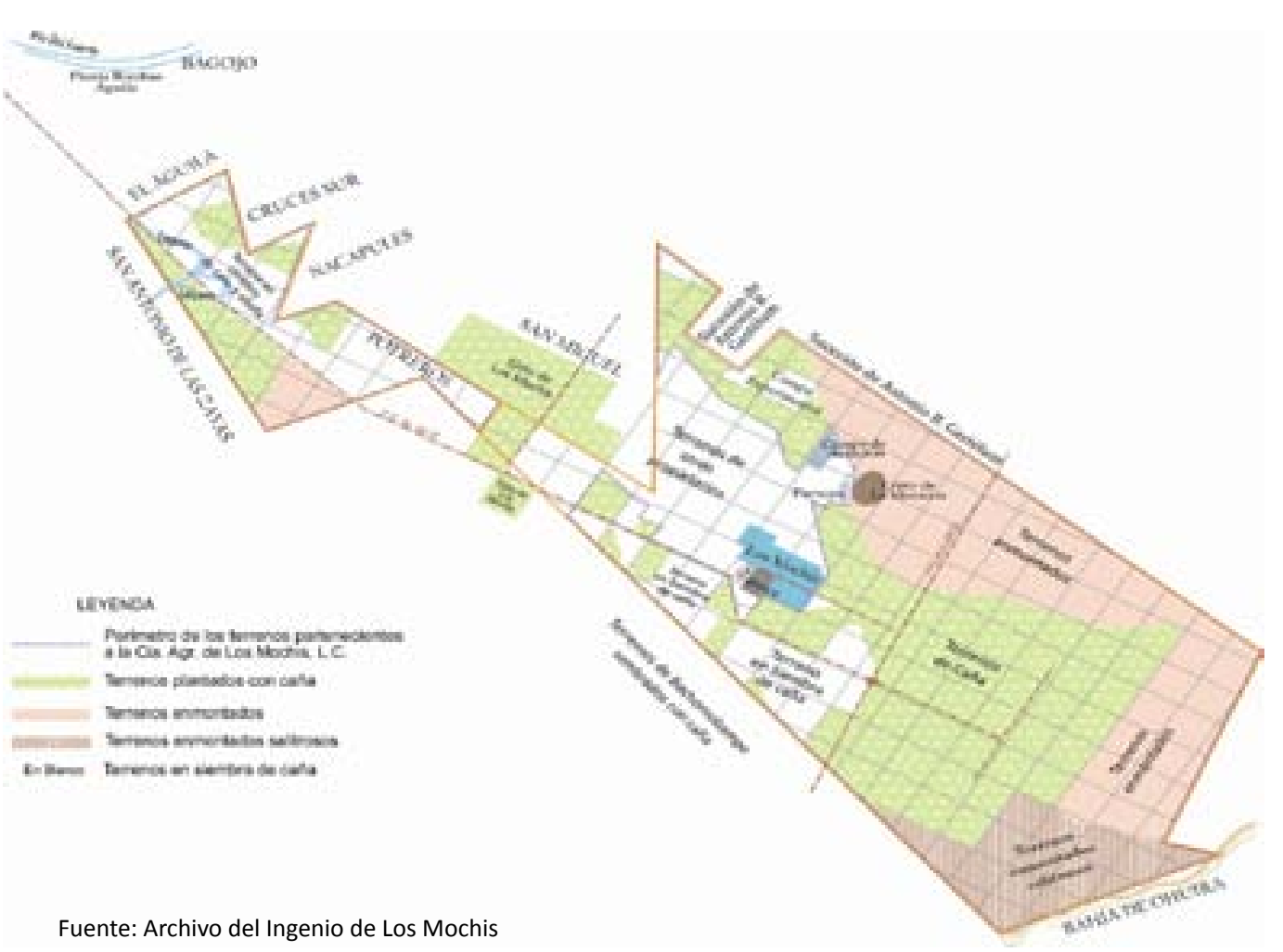

\section{CONSIDERACIONES FINALES}

A manera de conclusión, cabe mencionar que el proceso de aplicación de las leyes de repartimiento y tierras ociosas en el norte de Sinaloa modificó las relaciones sociales de los grupos indígenas. Su aplicación generó prácticas sociales que colocaron a los grupos más desprotegidos en un proceso de reorganización e innovación social, que trastocó varios aspectos de la vida rural y auspició un cisma de intranquilidad y rebeldía que se prolongó a lo largo de toda la segunda mitad del siglo XIX. En lo referente a las compañías deslindadoras su presencia en el norte de Sinaloa fue decisiva para acelerar el despojo de tierras a las comunidades indígenas.

Dicha situación originó una ruptura del tegumento de las costumbres de las comunidades indígenas. Estos detalles que pudieran parecer insignificantes en el curso del desarrollo económico, socavaron las relaciones tradicionales de los hombres con su entorno y sus medios de producción. Entre el conjunto de estrategias utilizadas por las élites económicas políticas del norte de Sinaloa, destacó la utilización de métodos muy variados como el uso de la fuerza militar de manera apabullante para luego proceder al fraccionamiento tanto desde el ámbito institucional y legal, mediante el uso de figuras de caciques que mediaron y se insertaron en los grupos inconformes, con la finalidad de establecer condiciones consensuales, al mismo tiempo de establecer los canales y las formas asociativas para amasar porciones de tierra.

Durante los años de la Revolución Mexicana, se presentó la oportunidad política para los indígenas mayos de desafiar por la vía de las armas a los hacendados. Algunas de sus expresiones fue la adhesión al movimiento armado y aceptaron combatir con la promesa que se les regresarían sus tierras comunales que antaño poseían. La mayoría de ellos laboraban en los ingenios de la USCO y las haciendas de la región. En este sentido, cabe destacar que cada grupo o facción recibe y moldea los discursos de acuerdo a sus intereses, lengua, etnicidad e historia. Por ello, cabe destacar que las particularidades étnico-culturales definen las formas de rebelión de los sujetos subalternos (Dube, 2001: 44-49, Chakrabaty, 1993: 93, Dube, 1999: 44).

Sus acciones de rebeldía fueron muy diversas desde el ataque a las instalaciones del ingenio Los Mochis, a los hacendados, enterrando canales, entre otras cosas. Por lo tanto no es casual que la primera huelga al interior de este ingenio allá sido al mismo tiempo, que si bien no tuvo mucho éxito significó un avance de las etapas del movimiento obrero. Durante la década 
de los veintes se vivió una etapa de reorganización del movimiento obrerocampesino, se incrementaron las demandas y hubo una mejor organización. A su vez, la empresa incrementó sus mecanismos de represión en abierta complicidad con el gobierno, tanto municipal como estatal.

Los trabajadores organizaron sindicatos generales, incorporando jornaleros de otras actividades agroindustriales, no solamente del ingenio Los Mochis. En respuesta la compañía fomentó el sindicalismo blanco y amenazó a quienes no se incorporaran a este sindicato, y de las amenazas pasaron a los hechos, recrudeciéndose la situación entre ambas partes.

Si bien, los empleados fueron reprimidos, lograron acercamientos que serian de suma utilidad posteriormente, pues este movimiento tuvo una buena acogida entre las capas laborales, lo cual se manifestó en apoyos de víveres, así como manifestaciones y marchas de apoyo para con el movimiento, también tuvieron respaldo a nivel nacional con un paro realizado por los trabajadores de los ingenios azucareros del país. Después de esto el movimiento obrero - campesino, entró en otra fase que se caracterizó por incorporar dinámicas diferentes a las etapas anteriores.

Entre las novedades se encuentran los paros parciales con la finalidad de mermar la producción del ingenio, acción secundada por los ingenios del centro del estado, y otros muchos a nivel nacional, esto nos refleja los lazos de solidaridad que los trabajadores de esta empresa habían establecido para esos años con otras regiones. Posteriormente los paros fueron totales y con carácter indefinido, firmándose contratos colectivos en más de una ocasión, los cuales USCO no respetó, mostrando una actitud desafiante tanto con sus trabajadores y con el gobierno en turno. En este marco emergió la figura de un líder, Carlos Ramón García Ceceña quien supo conducir la lucha adoptando otras medidas, al grado de acudir a la capital del país a entrevistarse, para plantearle la situación que imperaba.

Los trabajadores en esta última etapa siguieron nuevas tácticas frente a la necedad de la empresa de no hacer caso de los acuerdos anteriores. Los paros parciales se intensificaron, se implementaron nuevas estrategias de presión por parte de los obreros contra la empresa, la cual pudiera ser calificada de absurda o hasta irracional fue el haber matado de hambre a un número considerable de mulas propiedad de la compañía. Éste movimiento tomó otra dirección: las exigencias ya no fueron el incremento de salarios, la disminución de las jornadas laborales y un contrato colectivo de trabajo, la exigencia fue expropiación de las tierras del ingenio, cuestión que parecería extraña sin embargo no lo es.
Sobrevivientes que combatieron durante la revolución con la promesa de que se les devolverían sus tierras, caber recordar que muchos de ellos después de ésta lucha revolucionaria volvieron a incorporarse a laborar al seno de la empresa, pero ya no eran los mismos pues hubo una conciencia creciente de la propia identidad y unir esfuerzos. Al expropiarse finalmente los terrenos de United Sugar Companies se cerró una etapa de éste proceso de lucha, iniciándose otro con el nacimiento de la SICAE, proceso que requiere ser analizado desde otra perspectiva.

\section{REFERENCIAS}

Alarcón, Amézquita Saúl Armando (2006), Juan M. Banderas en la Revolución, (tesis de maestría en historia, inédita), Culiacán, Facultad de Historia-UAS.

Berstein Serge (1998), La cultura política, en Jean - Pierre Rioux y Jean Francois Sirinelli, Para una historia cultural, México, Taurus.

Cázares, Aboytes Pedro (2002), El gobierno de Macario Gaxiola y la United Sugar Companies, en Clio, Nueva Época, Vol. I, Número 27, Culiacán, Facultad de Historia-UAS, pp. 141-147.

--- (2004), La propiedad de la tierra y su evolución en el norte de Sinaloa: El caso de El Fuerte, en Clio, Nueva Época, Vol. I, Número 32, Culiacán, Facultad de Historia-UAS, pp. 132-154.

Chakrabaty, Dipesh (1999), Historia de las minorías, pasados subalternos, en Historia y Grafía, Número 12, México, Universidad Iberoamericana.

---, (2001), Sujetos Subalternos. Capítulos de una historia antropológica, México, COLMEX

Dube, Saurabh (1999), Introducción: temas e intersecciones de los pasados poscoloniales, en Saurabh Dube (Coordinador), Pasados poscoloniales. Colección de ensayos sobre la nueva historia y etnografía de la India, México, COLMEX.

Fradkin, Raúl (2006), La historia de una montonera, bandolerismo y caudillismo en Buenos Aires, 1826, Buenos Aires, Siglo XXI editores.

Fraser Ronald (2003), Identidades guerrilleras desconocidas. Las guerrillas españolas en la Guerra de Independencia, 1808-1814, historia social (Revista 
de la Fundación de historia social), número 46, Valencia

Fuentes Posadas Javier (2005), Una rebelión indígena al amparo de la Revolución: Felipe Bachomo y los mayos, 1913-1916, (tesis de licenciatura en historia, inédita), Culiacán, Facultad de historia-UAS.

Gill Mario (1983), La Conquista del Valle del Fuerte, Culiacán, U.A.S- I.I.E.S, (Colección Rescate número 19).

Joseph, M. Gilbert (2002), Para repensar la movilización revolucionaria en México: Las temporadas de turbulencia en Yucatán, 1909-1915. Gilbert M. Joseph y Daniel Nugent (Coordinadores), Aspectos cotidianos de la formación del Estado, México, Editorial Era.

Morett Jorge y María Luisa Pare (sin fecha), La pequeña Rusia: Las luchas de los trabajadores azucareros de Los Mochis, Sinaloa, 1924 - 1942, fotocopia.

Moore, Barrington (1996), La injusticia: bases sociales de la obediencia y la rebelión, México, UNAM.

Olea, R. Héctor (1993), La Revolución en Sinaloa, Culiacán, C.E.H.N, A.C.

Ortiz, Heras Manuel (1996) Violencia política en la II República y el primer franquismo, Madrid, Siglo XX editores.

Quintero, Leandro Filiberto (1978), Historia Integral de la región de la región del Río Fuerte, Los Mochis, Editorial El Debate.

Ramírez Meza Benito (1987) El movimiento Obrero Sinaloense en sus años de formación a la etapa de la crisis: 1875 - 1934, (tesis de maestría en Historia regional, inédita), Facultad de Historia, U.A.S, Culiacán.

--- (1994) Felipe Bachomo: Rebelión indígena y Revolución en la región de El Fuerte, Sinaloa, 1911 - 1916, en Ciencia y Universidad, I.I.E.S - U.A.S, Culiacán, Tercera Época, número 11, pp. 71-90

Rivera, Calvo María Elda (2001), Empresarios agrícolas en Ahome: 1929 1940, [tesis de maestría en historia, inédita], Culiacán, Facultad de HistoriaU.A.S.

Schobert, Lorena (1998), Historia de una gesta obrera campesina: La SICAE, Culiacán, DIFOCUR.

Scott James (2000), Los dominados y el arte de la resistencia, Discursos ocultos, México, Editorial Era.

Thompson P. Edward (1989), La formación de la clase obrera en Inglaterra, Barcelona, II Tomos, Editorial Crítica.

Tilly, Charles (2000), Las revoluciones europeas, 1492-1992, Barcelona, Editorial Crítica

Torrow, Sidney (1997), El poder en movimiento. Los movimientos sociales, la acción colectiva y la política, Madrid, Alianza Universidad.

Vidales, Quintero Mayra Lizzete (2002), El reparto agrario en Sinaloa: la política antiagrarista de Ángel Flores en Gustavo Aguilar Aguilar et. al., [Compiladores], Historia de Sinaloa y otras regiones, Memoria del XII Congreso Nacional de Historia Regional, Culiacán, Facultad de Historia-UAS.

Vovelle, Michel (2000), Introducción a la Revolución Francesa, Barcelona, Editorial Crítica.

Fuentes de archivo

Archivo Histórico General del Estado de Sinaloa

ndice de Correspondencias de la Secretaría de Gobierno, años 1866, 1869 1887-1888, 1910-1911, 1913, 1916, 1918.

Archivo del Ingenio de Los Mochis, caja s/n, 1934

Archivo Municipal del Ayuntamiento de El Fuerte, 1869, 1905.

Archivo del Registro Agrario Nacional/Sinaloa, 1938

Prensa

Estado de Sinaloa, 1925-1937

Las Noticias, 1938

El Demócrata Sinaloense, 1926

\section{Pedro Cázares Aboytes.}

perryyorke55@hotmail.com

icenciado y maestro en Historia por la Universidad Autónoma de Sinaloa. Estudiante del Doctorado en Ciencias Sociales en la Universidad de Guadalajara. Profesor asignatura en la Universidad Autónoma de Sinaloa. Autor del libro "Heraclio Bernal, entre la rebeldía y el bandolerismo,"asi como de artículos en revistas y capítulos de libros sobre historia social del delito, movimientos sociales y grupos indígenas durante el siglo XIX y Revolución Mexicana. Ponente en congresos nacionales e internacionales y conferencista en varias universidades. 